\title{
The chromosome complement of Sorex granarius-the ancestral karyotype of the common shrew (Sorex araneus)?
}

\author{
J. M. Wójcik* and \\ J. B. Searle†
}

\author{
* Mammals Research Institute, Polish Academy of \\ Sciences, 17-230 Bialowieza, Poland. \\ $\uparrow$ Department of Zoology, University of Oxford, \\ South Parks Road, Oxford OX1 3PS, U.K.
}

We present the G-band karyotype of Sorex granarius (Miller, 1910). With minor exceptions, each of the acrocentric autosomes in this karyotype is completely homologous to one of the chromosome arms in the karyotype of the common shrew (Sorex araneus L., 1758). If, as is the simplest interpretation, the karyotypic evolution in $S$. araneus is by repeated Robertsonian fusion, the karyotype in $S$. granarius represents the ancestral condition. We urge breeding studies to establish whether the designation of $S$. granarius as a full species is justified.

\section{INTRODUCTION}

The common shrew (Sorex araneus L., 1758) has one of the most variable karyotypes of any mammal. Consequently, wild populations throughout its range have been the subject of much cytogenetic analysis, particularly in recent years (e.g., Belcheva and Kolevska, 1986; Fedyk, 1986; Hausser et al., 1986; Searle, 1986a, b, 1987; Wójcik, 1986; Fedyk and Leniec, 1987; Halkka et al., 1987; Searle and Wilkinson, 1987; Wójcik and Zima, 1987; Fredga, 1987). The species initially attracted interest (Sharman, 1956; Ford et al., 1957) because it displays karyotypic polymorphism of a Robertsonian type, such that individuals within a population vary in chromosome number while the number of chromosome arms (the nombre fondamental) in the karyotype remains constant. In areas of polymorphism, a particular chromosome arm may occur unattached (i.e., as an acrocentric) or fused to another chromosome arm (i.e., as part of a metacentric). In the 1970s it was demonstrated, with the aid of chromosome banding techniques, that the metacentrics may be composed of different combinations of chromosome arms in different parts of the range of the species (Fredga, 1973; Fredga and Nawrin, 1977). These sets of metacentrics occur in discrete geographical areas and may be considered to define distinct karyotypic races which form a patchwork throughout the northern Palaearctic range occupied by the species (e.g., in Sweden: Fredga and Nawrin, 1977; in Siberia: Král et al., 1981; in Britain: Searle, 1984).
In terms of chromosomal (structural) mutations, the simplest explanation for this variation is that the ancestral karyotype of the common shrew consisted of acrocentric chromosomes. On this hypothesis, the polytypic variation arises from different pairs of the ancestral acrocentric chromosomes having joined at their centromeric ends (a process generally termed Robertsonian, or centric, fusion) to form different, race-specific, combinations of metacentrics. If this is the case, the Robertsonian polymorphism can be considered to result when both the ancestral acrocentric chromosomes and the derived metacentric chromosomes are present in the same population. Thus, one can explain the karyotypic variation in the common shrew in terms of a single type of mutation, the Robertsonian fusion of ancestral acrocentric chromosomes. An alternative, and less parsimonious, hypothesis is that the observed karyotypic variation arose from ancestral metacentric chromosomes by two types of structural mutation: Robertsonian (or centric) fission and either Robertsonian fusion or whole-arm reciprocal translocation. All these forms of mutation have been well-demonstrated in mammals (e.g., Robertsonian fusion in mouse: Léonard and Deknudt, 1967; Robertsonian fission in the shrew $S$. coronatus: Olert, 1973; whole-arm reciprocal translocation in mouse: Crocker and Cattanach, 1981). On the assumption of an ancestral acrocentric karyotype and only Robertsonian fusion mutations, Searle (1984) constructed a phylogeny for the known karyotypic races of the common shrew, 
which fitted well with the geographic distribution of these races.

Of the chromosome arms within the karyotype of the common shrew, it is those autosomes labelled $g-r$ on the basis of G-banding pattern (Halkka et al., 1974; Fredga and Nawrin, 1977) which display Robertsonian variation. The sex chromosome complement is invariant and similar to other species within what is now known as the $S$. araneus complex (Hausser et al., 1985), these all have an $\mathrm{XX} / \mathrm{XY}_{1} \mathrm{Y}_{2}$ system (Fredga, 1970). The remaining six autosome arms $(a, b, c, f, t, u)$ are always present combined in the metacentrics $a f, b c$ and $t u$ in the common shrew karyotype. In this paper we seek evidence whether these metacentrics, in addition to those composed of chromosome arms $g-r$, could be products of Robertsonian fusion.

Within the $S$. araneus complex there are a number of species which are morphologically extremely similar to $S$. araneus. One of these is the Iberian species, S. granarius (Miller, 1910), which was of great interest to us because conventional chromosome preparations had revealed an acrocentric autosome karyotype with characteristics similar to those expected in the putative ancestral karyotype of $S$. araneus (Hausser et al., 1985). To examine the homology of the chromosomes of $S$. araneus and $S$. granarius, it was essential to obtain good G-banded preparations of $S$. granarius. One of us, J. M. W., collected one male and one female of this species from La Granja, Segovia, Spain in May 1987 and made mitotic chromosome preparations according to a standard method (Wójcik, 1986) after injection with colcemid (a metaphase arrestant).

\section{RESULTS AND DISCUSSION}

A G-banded karyotype of the female $S$. granarius is shown in fig. 1 . The chromosome number is $2 n=36$, and was $2 n=37$ for the male, in confirmation of the findings of Hausser et al. (1985). In both individuals all the autosomes were acrocentric, except for one pair, where there was polymorphism between a metacentric and an acrocentric state; the male was homozygous acrocentric and the female heterozygous (fig. 1). Hausser et al. (1985) report this polymorphism and illustrate a heterozygous male.

All the chromosomes of $S$. granarius appear homologous, or nearly so, to the chromosomes of the common shrew and can be labelled by the same nomenclature (figs. 1 and 2). The sex chromosome

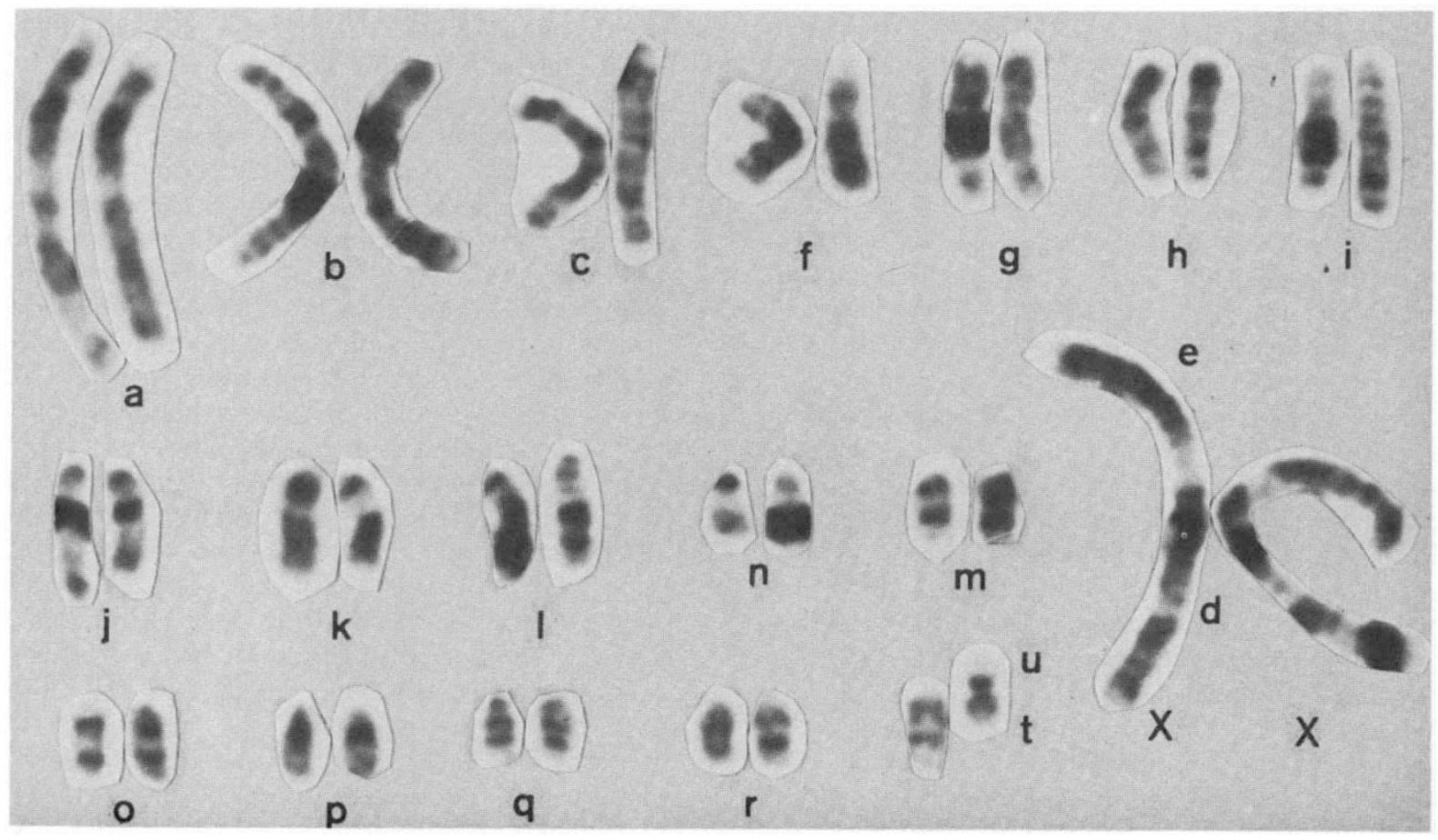

Figure 1 G-band karyotype of female $S$. granarius, with each arm labelled according to the standard nomenclature system of the common shrew (Halkka et al., 1974; Fredga and Nawrin, 1977). 


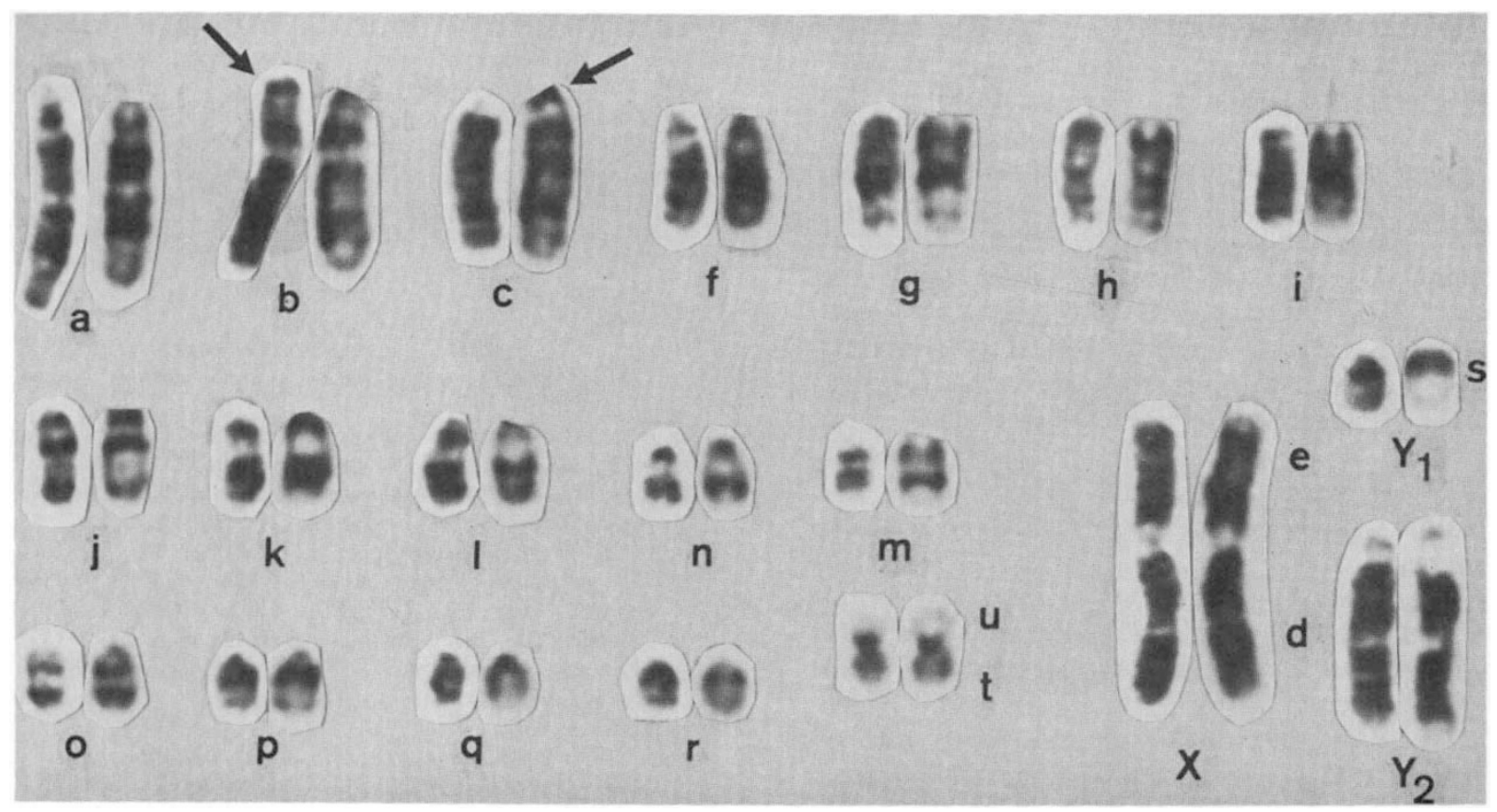

Figure 2 Comparison between G-banded chromosome arms of $S$. granarius (left) and $S$. araneus. In each case, all chromosomes are cut from a single spread except for the $t u$ of $S$. granarius which is the same as that illustrated in fig. 1 . For $S$. araneus it was necessary to cut metacentrics $a f, b c, j l, h i$ and $g m$ at their centromeres for this comparison. Arrows indicate a dark band that is present on chromosome $b$ of $S$. granarius but on chromosome arm $c$ of $S$. araneus.

set appears identical in the two species and the autosomes of $S$. granarius (with the exception of the polymorphic pair) are apparently homologous with the chromosome arms $a-c$ and $f-r$ of $S$. araneus. The metacentric state of the polymorphic pair in $S$. granarius is homologous to $t u$ of $S$. araneus. Thus, in essence, the karyotype of $S$. granarius is the expected ancestral acrocentric karyotype of the common shrew on the simplest model of karyotype evolution, repeated Robertsonian fusion. Even two of those autosomes which are invariably metacentric in the common shrew karyotype, $a f$ and $b c$, are found as acrocentrics $a$, $b, c$ and $f$ in $S$. granarius.

To a minor degree the karyotypic variation in $S$. granarius and $S$. araneus cannot wholly be explained, in a mutational sense, by Robertsonian fusions:

(a) There is a centromeric dark band on chromosome arm $b$ (but not $c$ ) of $S$. granarius while such a band is found on chromosome arm $c$ of $S$. araneus (fig. 2). This can most simply be explained by either a pericentric inversion or a centric shift in the metacentric $b c$ of $S$. araneus (or a karyotypic intermediate between $S$. araneus and $S$. granarius). Clearly, banding on prometaphase chromosomes or synap- tonemal complex analysis in hybrids should resolve the mutation involved.

(b) The karyotypic polymorphism in $S$. granarius involving one of the small autosome pairs is not of a Robertsonian type (fig. 1). Instead the chromosome number remains constant in the different karyomorphs while the nombre fondamental changes. The metacentric form of $t u$ may differ from the acrocentric state by either a pericentric inversion or a centric shift. The former would appear more likely on the basis of chromosome band pattern (fig. 1), but prometaphase banding analysis and a study of the synaptonemal complexes of hybrids would be desirable.

(c) When chromosome arm $j$ is in the acrocentric state in $S$. araneus (not illustrated) it has a distinct short arm, while acrocentric $j$ in $S$. granarius has a terminal centromere. (This is particularly clear in conventional preparations: Fredga, 1973; Hausser et al., 1985; J. M. Wójcik and J. B. Searle, unpublished data.) As chromosome arm $j$ appears to have the same banding pattern when an acrocentric in both $S$. granarius and $S$. araneus and when part of a metacentric in $S$. araneus, it would appear that $\operatorname{arm} j$ in the acrocentric condition 
in $S$. araneus differs from the other states of $j$ by a centric shift. This is discussed further in Searle and Fredga (in preparation).

Thus the chromosome complement of $S$. granarius may be closely similar to the ancestral karyotype of $S$. araneus, with autosome arms $a-c$, $f-r$ present as acrocentrics (while all these arms can be present in metacentrics in $S$. araneus and $a, b, c$ and $f$ always are), but with $t u$, at least in some individuals of $S$. granarius, already in a metacentric state. However, to support this scheme of karyotypic evolution it is desirable to make a much larger comparison within the $S$. araneus complex and elsewhere within the genus Sorex. V. T. Volobouev (personal communication) is attempting such an analysis.

Finally, we would like to raise some taxonomic issues. Catzeflis et al. (1982) show that biochemical markers fail to separate $S$. granarius and $S$. araneus and recent papers by Hausser (1984) and Hausser et al. (1985) raise doubts about the significance of previously reported morphological differences between the species (Hausser et al., 1975). Our karyotypic studies indicate that apart from some minor rearrangements involving chromosome $t u$ (which are not always present) and chromosome arms $b, c$ and $j$, there is less difference between $S$. granarius and some of the most acrocentric karyotypes of $S$. araneus than between some karyotypes within the species $S$. araneus. Sorex granarius and $S$. araneus are at present allopatric, so it is not possible to determine, without intrusive experiments, whether they are good biological species. However, attempts should be made in captivity, and preferably in a semi-natural situation, to determine whether these soricines will interbreed and if so, the extent of hybrid unfitness (and the contribution of karyotypic difference to any fitness reduction).

Acknowledgements We would like to thank Dr Santiago Reig Redondo for his help with collections. Dr Angela Douglas kindly read through the manuscript. J. B. S. is supported by the Royal Society of London.

\section{REFERENCES}

BElCheva, R. G. AND KOlevSKA, N. G. 1986. Cytogenetic studies of the common shrew Sorex araneus L. (Soricidae, Insectivora) from the Vitosha mountain. Comptes rendus de l'Académie bulgare des Sciences, 39, 115-118.

CATZEFLIS, F., GRAF, J.-D., HAUSSER, J. AND VOGEL, P. 1982. Comparaison biochimique des Musaraignes du genre Sorex en Europe occidentale (Soricidae, Mammalia). Z. f. zool. Systematik u. Evolutionsforschung, 20, 223-233.
CROCKER, M. AND CATTANACH, B. M. 1981. X-ray induction of translocations in mice carrying metacentrics (Robertsonian fusions); detection of whole arm chromosome exchanges. Mutation Research, 91, 353-357.

FEDYK, S. 1986. Genetic differentiation of Polish populations of Sorex araneus L. II. Possibilities of gene flow between chromosome races. Bull. Acad. Pol. Sci., 34, 161-171.

FEDYK, S. AND LENIEC, H. 1987. Genetic differentiation of Polish populations of Sorex araneus L. I. Variability of autosome arm combinations. Folia Biol. (Kraków), 35, $57-68$.

FORD, C. E., HAMERTON, J. L. AND SHARMAN, G. B. 1957. Chromosome polymorphism in the common shrew. Nature, 180, 392-393.

FREDGA, K. 1970. Unusual sex chromosome inheritance in mammals. Phil. Trans. R. Soc. Lond., B259, 15-36.

FREDGA, K. 1973. A new chromosome race of the common shrew (Sorex araneus) in Sweden. Hereditas, 73, 153-157.

FREDGA, K. 1987. Chromosome races of the common shrew (Sorex araneus) in Sweden. What happens in the hybrid zones? In Brandham, P. E. (ed.) Kew Chromosome Conference III, Allen and Unwin, London (In press).

FREDGA, K. AND NAWRIN, J. 1977. Karyotype variability in Sorex araneus L. (Insectivora, Mammalia). Chromosomes Today, 6, 153-161.

HALKKA, L., HALKKA, O., SKARÉN, U. AND SÖDERLUND, V. 1974. Chromosome banding pattern in a polymorphic population of Sorex araneus from northeastern Finland. Hereditas, 76, 305-314.

HALKKA, L., SÖDERLUND, V., SKARÉN, U. AND HEIKKILÄ, J. 1987. Chromosomal polymorphism and racial evolution of Sorex araneus L. in Finland. Hereditas, 106, 257-275.

HAUSSER, J. 1984. Genetic drift and selection: Their respective weights in the morphological and genetic differentiation of four species of shrews in southern Europe (Insectivora, Soricidae). Z. f. zool. Systematik u. Evolutionsforschung, 22, 302-320.

HAUSSER, J., GRAF, J.-D. AND MEYLAN, A. 1975. Donńees nouvelles sur les Sorex d'Espagne et des Pyrénées (Mammalia, Insectivora). Bull. Soc. Vaud. Sc. Nat., 348, 241-252.

HAUSSER, J., CATZEFLIS, F, MEYLAN, A. AND VOGEL, P. 1985. Speciation in the Sorex araneus complex (Mammalia: Insectivora). Acta Zool. Fennica, 170, 125-130.

HAUSSER, J., DANNELID, E. AND CATZEFLIS, F. 1986. Distribution of two karyotypic races of Sorex araneus (Insectivora, Soricidae) in Switzerland and the post-glacial recolonisation of the Valais: First results. $Z$. f. zool. Systematik $u$. Evolutionsforschung, 24, 307-314.

KRÁL, B., ANISKIN, V. M. AND VOLOBOUEV, V. T. 1981. Karyotype variability in Siberian populations of Sorex araneus (Soricidae, Insectivora). Folia Zool. Brno, 30, 23-37.

LÉONARD, A. AND DEKNUDT, G. H. 1967. A new' marker for chromosome studies in the mouse. Nature, 214, 504-505.

OLERT, J. 1973. A case of chromosome dissociation in a shrew. Genet. Res., 22, 323-324.

SEARLE, J. B. 1984. Three new karyotypic races of the common shrew Sorex araneus (Mammalia: Insectivora) and phylogeny: Syst. Zool, 33, 184-194.

SEARLE, J. B. $1986 a$. Meiotic studies of Robertsonian heterozygotes from natural populations of the common shrew, Sorex araneus L. Cytogenet. Cell Gent., 41, 154-162.

SEARLE, J. B. $1986 b$. Factors responsible for a karyotypic polymorphism in the common shrew. Sorex araneus. Proc. $R$. Soc. Lond., B229, 277-298.

SEARLE, J. B. 1987. Karyotypic variation and evolution in the common shrew Sorex araneus. In Brandham, P. E. (ed.) Kew Chromosome Conference III, Allen and Unwin, London (In press). 
SEARLE, J. B. AND WILKINSON, P. J. 1987. Karyotypic variation in the common shrew (Sorex araneus) in Britain-a "Celtic Fringe". Heredity, 59, 345-351.

SHARMAN, G. B. 1956. Chromosomes of the common shrew. Nature, 177, 941-942.
WÓJCIK, J. M. 1986. Karyotypic races of the common shrew (Sorex araneus L.) from northern Poland. Experientia, 42, 960-962.

WÓJCIK, J. M. AND ZIMA, J. 1987. Cytogenetics of the common shrew (Sorex araneus Linnaeus, 1758). Przegl. Zool., 31, 439-456 (In Polish). 